\title{
Amores oblicuos sobre paisaje en guerra: el colaboracionismo en Suite francesa de Irène Némirovsky
}

\author{
Carlos BRITO DÍAZ \\ Departamento de Filología Española \\ Universidad de La Laguna \\ cbridiaz@ull.edu.es
}

\begin{abstract}
RESUMEN
Irène Némirovsky traza uno de los primeros testimonios literarios de la Segunda Guerra Mundial pues el tempo novelesco es contiguo a los acontecimientos de la historia simultánea. La versión cinematográfica reciente del bestseller (Saul Dibb, 2015) atiende a uno de los dos relatos conservados, Dolce, sobre la primera ocupación alemana de Francia en 1940. Alejada de la narración romántica, cinta y relato narrativo convocan un fresco descriptivo -aval del estilo minucioso de la autora- que descubre las guerras íntimas y minúsculas subsumidas en el gran decorado del conflicto internacional, en las que pespuntan la crueldad, la muerte y la sinrazón predecibles en continuidad con la valentía, la solidaridad y la entereza moral improbables. De las dos partes conservadas, la primera (Tempestad en junio) se articula sobre cuadros narrativos que fijan la visión en la hecatombe; la segunda, Dulce, es una novela que ahonda en las diversas formas de colaboracionismo.
\end{abstract}

Palabras clave: Némirovsky, colaboracionismo, ocupación, Segunda Guerra Mundial.

\section{Mixed loves with a belic landscape: the collaborationist policy in French Suite by Irène Némirovsky}

\begin{abstract}
Irène Némirovsky writes one of the earliest literary evidence of the Second World War as the novelistic tempo is adjacent to the events of history simultaneously. The recent film version of the bestseller (Saul Dibb, 2015) serves one of the two accounts preserved, Dolce, on the first German occupation of France in 1940. Away from the romantic narrative, film and narrative story organized one descriptive picture -detailed exemple of description style author- discovering the intimate and sensitive wars subsumed in the great decorated international conflict, in which the predictable cruelty, death and unreason stand in continuity with courage, solidarity and moral integrity unlikely. Of the two conserved parts, the first (Storm in June) is articulated on fixing Storyboards vision in the slaughter; the second, Dulce, is a novel that delves into the various forms of collaboration.
\end{abstract}

Keywords: Némirovsky, collaboration, occupation, Second World War. 
En la escritora ucraniana Irène Némirovsky (1903-1942) se salda el signo de la paradoja: el hallazgo tardío de su novela Suite francesa es uno de los más tempranos acercamientos coetáneos a la conmoción socio-moral que siguió al estallido de la Segunda Guerra Mundial, al margen de sus desórdenes político, económico y geográfico. El hallazgo del manuscrito, caligrafiado en apretada letra para ahorrar papel, en una maleta que vagó de refugio en refugio de la mano de sus hijas fugitivas $^{1}$ precipita la credencial de una autora que resarció con su arte narrativo una deuda póstuma con el país que nunca la aceptó del todo ni le concedió la legitimidad: Francia. Muchos años después de su muerte, tal vez demasiados, tras vencer dolorosos y punzantes recuerdos, Denise Epstein, la hija de la escritora, descubre el texto de la novela en el cuaderno conservado y decide transcribir con una lupa la letra minuciosa en la que dormía el sueño de la inercia su obra más destacable, Suite francesa, publicada por vez primera por la editorial francesa Denoël en $2004^{2}$ con un prólogo de Myriam Anissimov, notas manuscritas de la autora sobre la situación de Francia y sobre su proyecto narrativo en cinco obras (de las que solo concluyó las dos primeras), y la correspondencia mantenida entre 1936 y 1945 por Irène Némirovsky, su marido, Michael Epstein, el editor Albin Michel, Robert Esménard, yerno de este, la secretaria de la editorial la señorita Le Fur, el director literario André Sabatier, su amiga Madeleine Cabour, su cuñada Mavlik Epstein, así como las cartas cruzadas con algunas autoridades, nobles, dignatarios y personas vinculadas al ambiente intelectual.

Considerada una escritora puente entre la literatura eslava y la de la $S h o a h^{3}$ y amén de otras obras publicadas en vida de la autora ${ }^{4}$, fue especialmente la novela

${ }^{1}$ Sobre el signo vital del abandono en la escritora véase la reseña a la novela de María Aixa Sanz (2007).

${ }^{2}$ La edición española se publicó el año siguiente por la Editorial Salamandra con traducción de José Antonio Soriano Marco: citaremos por la 24 edición (2015). Obtuvo en 2006 el Premio Renaudot al Libro del Año 2005 (Manrique Sabogal 2006).

3 «De hecho, se puede hablar de la emergencia de todo un género que ya se conoce como la «literatura de la Shoah» (término preferido en los últimos años al de «Holocausto») que englobaría aquella producción literaria realizada bien por testigos, supervivientes o víctimas implicadas directamente en el exterminio de los judíos europeos, bien por escritores que lo han convertido en tema de sus obras, presidida por la intención de dejar testimonio y contribuir a que «nunca más» suceda nada semejante. Asimismo, la llamada «literatura concentracionaria» o literatura «de los campos» podría ser incluida en este dominio. Y, aunque no se suelen incorporar a él, la proliferación de novelas, relatos y películas de éxito acerca de lo acontecido en Europa durante la primera mitad del siglo XX, desde Las benévolas a El niño del pijama de rayas, desde La lista de Schindler a El lector, El pianista o La vida es bella, no pueden por menos que añadirse al gran volumen de literatura (y arte) producido no ya «después de» sino «sobre» Auschwitz. En esta inmensa cantidad de escritura, sin embargo -paradójicamente-, la «poesía», esa privilegiada representante de la cultura esgrimida en la famosa frase, ha representado una fracción diminuta cuantitativamente hablando: novelas, memorias, autobiografías, reportajes o filmes ocupan la mayor parte de lo dicho» (Sánchez 2015).

${ }^{4}$ Las primeras obras narrativas de Némirovsky aparecen a finales de la década de los años veinte (los relatos Un niño prodigio, La enemiga y El malentendido [1926-1930]); siguen dos novelas «judías», David Golder (19129) y El baile (1930), dos novelas rusas, Nieve en otoño (1931) y El caso Kurílov (1933), novelas de asunto francés (El peón en el tablero [1934], Películas habladas [1934], El vino 
David Golder, editada en 1929 y llevada al cine por Julien Duvivier en $1931^{5}$, la que le otorgó un lugar de prestigio en la narrativa francesa de su tiempo: el personaje central, un banquero inspirado en la figura de su propio padre, fue protagonizado por el actor judío Harry Baur que murió en París a causa de una paliza propinada por los mismos nazis con los que había colaborado.

El cuaderno con las iniciales de la autora que vagó itinerante contenía un sabroso complemento metatextual con notas, apostillas y reflexiones de la autora sobre el proceso de la escritura: allí perfila líneas de conducta, anota necesidades de documentación, razona sobre la lógica narrativa, descubre su cronograma de redacción, arguye referencias musicales (de importancia simbólica en la Suite desde su propio título), agrega comentarios a lo ya escrito, desliza digresiones acerca de la longitud de sus narraciones, sobre la secuencia de personajes o sobre el plan narrativo gene-

de la soledad [1935], un intermezzo autobiográfico - Jezabel [1936]-, La presa [1938] y Dos [1939]), narraciones sobre la marginación y el exilio (Fraternidad [1937], El maestro de almas [1939] y Los perros y los lobos [1940]) y dos novelas póstumas sobre el amor a la tierra (Los bienes de este mundo [1941] y Fogatas [1942]. Completan su producción, al margen de sus notas en prensa, las novelas de la «resurrección»: Suite francesa (2004) y El ardor de la sangre (2007), cuyo descubrimiento fue saludado por la prensa (Octavi Martí 2004 y 2006 y Francisco Solano 2005). La Editorial Salamandra, tras la irrupción de Suite francesa en 2005, ha ido editado sucesivamente David Golder, El ardor de la sangre, El baile, El maestro de almas, El caso Kurílov, Nieve en otoño, Los perros y los lobos, El vino de la soledad, Jezabel, El malentendido, Los bienes de este mundo y La presa. A falta de otros, el mejor estudio hasta el momento sobre la obra de Némirovsky es el de Kershaw (2009), adelantado en un artículo (2007), de la que Olivier Philipponnat (2009) en su reseña advertía de las diferentes perspectivas críticas con las que se ha juzgado a la autora (rusa o francesa, estilo femenino o masculino, semita o no en su escritura predominantemente satírica): «On discute de savoir si Némirovsky est un auteur russe ou français, si son style est féminin ou masculin, s'il appartenait à un Juive, fille de banquier de surcroît, d'ecrire une «satire sociale acerbe» des milieux d'affaires. De sorte que ce concert de louanges et de surenchères - processus de «mythologisation»-, bientôt suspect, provoque dans un second temps une série de mises en cause, par réflexe de ne pas s'en laisser conter». Es coautor de una biografía en la que se analizan sus obras en relación con el periplo vital de la autora (2007). Coeetze (2008) también insiste en el modelo de Tolstoi y en la filiación chejoviana de la escritura de Némirovsky: «With its large cast of characters and wide social range, Suite française is more ambitious than anything Némirovsky had previously attempted. In it she takes a hard look at France during the Blitzkrieg and the subsequent occupation. She saw herself as following in the line of Chekhov, who had addressed the «mediocrity» of his times «without anger and without disgust, but with the pity it deserved». In preparation for her task she also reread War and Peace, studying Toltoy's method of rendering history indirectly through the eyes of his characters». Sobre el discutido ideario judío de la escritora, véase Octavi Martí (2007). En España la referencia de Manuel Chaves Nogales (recogido en 2011: 301-303) en unos reportajes del diario Ahora de 1931 se tiene como la primera noticia de la autora. Debemos a José Giménez Corbatón (1999a y 1999b) uno de los pocos análisis generales de la narrativa de Némirovsky en nuestro país.

${ }_{5}$ El cuidadoso estilo de Némirovsky se anuncia en su primera obra: la capacidad descriptiva, la combinación entre humanidad y vileza de sus personajes, el ritmo sobrio y sintético de la acción, la simbólica circularidad del relato, que comienza y precipita en la muerte, enuncian a la escritora de la Suite. Las palabras finales de la novela deslizan un tono melancólico en la concepción inmisericorde con la que perfila a su protagonista: «Oyó que lo llamaban: «David... David...». Era una voz amortiguada por la nieve, el cielo bajo y la oscuridad, una voz débil que se perdía y de pronto cesaba, como obstaculizada por el recodo de un camino. Fue el último sonido del mundo que penetró en él» (2006: 158).

Revista de Filología Románica 
ral, entre otros aspectos, al tiempo que delata su admirable capacidad de análisis de la hirviente realidad europea próxima: «Francia va a ir de la mano de Alemania. Aquí se movilizará pronto, «pero solo a los jóvenes»... Un ejército atraviesa Rusia, el otro viene de África. Suez ha caído. Japón vence a Estados Unidos con su formidable flota. Inglaterra pide clemencia» (2015: 417), o su ironía amarga cuando apostilla del pensamiento irracional del nazismo en ciernes («Hitler: "No lucho por mí sino por Europa" (empezó diciendo: "no lucho por el pueblo alemán”. Piensa como Napoleón: "la vida y la muerte de millones de hombres me importan un comino")» [2015: 421]); también desliza su decepción por la negativa de Francia a concederle la nacionalidad:

¡Dios mío! ¿Qué me hace este país? Ya que me rechaza, considerémoslo fríamente, observémoslo mientras pierde el honor y la vida. Y los otros ¿qué son para mí? Los imperios mueren. Nada tiene importancia. Se mire desde el punto de vista místico o desde el punto de vista personal, es lo mismo. Conservemos la cabeza fría. Endurezcamos el corazón. Esperemos. (2015: 421)

Estas notas dan la pista de una escritora minuciosa, atenta al detalle, con una precisa visión de su cosmos narrativo, con guiños intertextuales de cohesión entre las piezas, dotada de una notable capacidad especulativa para establecer prioridades en su ficción y, sobre todo, clara y coherente con los objetivos trazados previamente; refiriéndose a Dolce, la segunda y última de las piezas conservadas de su prevista pentalogía, concluye: «Lo más importante aquí, y lo más interesante, es lo siguiente: los hechos históricos, revolucionarios, etc., solo hay que rozarlos, mientras se profundiza en la vida cotidiana y afectiva, y, sobre todo, en la comedia que eso ofrece» (2015: 435). Y esta es una de las claves interpretativas de su narrativa: su intención de servir la historia en minúsculas alejada de imposturas épicas para hacer converger todos los puntos de fuga sobre la condición humana.

Es curioso comprobar la omnisciencia de la autora sobre su plan narrativo: Irène desbroza incluso la extensión de las cinco piezas de su proyecto original (Tempestad en junio, Dolce -las dos únicas conclusas-, Cautividad, Batallas y La paz, estos dos últimos títulos entre interrogantes de la propia escritora), si bien plantea sus dudas acerca de la continuidad e hilación entre sus piezas («Pese a todo, lo que une a todos estos seres es la época, únicamente la época. ¿Es suficiente? Quiero decir: ¿se siente suficientemente ese lazo?» [2015: 427]).

La primera de las piezas de su Suite es Tempestad en junio, un delicioso collage de episodios que, merced a la técnica de un minucioso descriptivismo, nos presenta un caleidoscopio de historias mínimas al calor de la primera ocupación alemana de Francia en 1940 y de la terrible diáspora egoísta de los parisinos que brindó la capital a los nazis sin oponer resistencia. Una velada crítica de esta indolencia civil subyace en el inmisericorde repertorio de gestos egoístas e insolidarios que menudean en la conducta de los fugitivos, al tiempo que exhibe cómo la ley de la resiliencia va minando la dignidad y el respeto colectivos al exponer a individuos acostumbrados a una vida de privilegios a situaciones de desamparo: burgueses acomodados con sus criados, un escritor de fama y su amada con el chófer y la doncella, descen- 
dientes de nobles, un banquero y su amante, un sacerdote y un grupo de niños de un orfanato, unos empleados de banca, un viejo rentista, un muchacho voluntario para la lucha, una bailarina que oficia de intrigante o el gato Albert en cuya perspectiva felina se instala el narrador omnisciente en un delicioso capítulo. Todos ellos son jirones de una humanidad que observa la irrupción de la guerra con desdén distante, como si el conflicto fuera un inoportuno desorden tras del cual todo habría cambiado para seguir siendo lo mismo; con sutil agudeza la escritora traza una lúcida reflexión sexista en boca de la frívola Arlette Corail:

Habría nuevos ricos, como al día siguiente de cualquier desastre; hombres dispuestos a pagar caros sus placeres, porque habían obtenido su riqueza sin esfuerzo, y el amor seguiría siendo lo de siempre. Pero, por Dios, ique aquel caos acabara cuanto antes! Que se implantara un estilo de vida, fuera el que fuese; puede que todo aquello, aquella guerra, las revoluciones, los grandes acontecimientos de la Historia, excitara a los hombres, pero para las mujeres... ¡Ah, para las mujeres solo era un fastidio! Estaba segura de que, a ese respecto, todas pensaban como ella: ¿las grandes palabras, los grandes sentimientos? Una monserga, un tostón como para aburrir hasta las piedras. Ah, los hombres... Había cosas en las que aquellos seres tan simples resultaban incomprensibles. Pero las mujeres estaban curadas durante al menos cincuenta años de todo lo que no fuera vida cotidiana, las cosas tangibles... (2015: 133)

A medida que avanza este relato en caleidoscopio el conjunto humano va degenerando en selva porque Némirovsky nos convierte en testigos incómodos de un proceso de descomposición socio-moral, paralelo al tránsito de los fugitivos de París al campo, en un descenso a la condición animal donde se dinamita el sentido común y se desintegra la colectividad, para dejar paso a ciegas individuales entregadas al ejercicio de la supervivencia. Bajo el ciego proceder del miedo, la indolencia o la progresiva pérdida de la dignidad la guerra se anuncia como un acontecimiento falsamente lejano, que irrumpe con letal imprevisión mientras arrecian los bombardeos en la ruta de la diáspora hacia el campo. Hasta entonces, y ni siquiera tras estas demostraciones de violencia, no hay en los personajes conciencia de la ocupación ni de la consumada invasión imparable. La autora escribe al calor de los sucesos, sin la perspectiva que otorga el tiempo, con una cercanía rayana en la simultaneidad de los acontecimientos, y pespunta una de las primeras crónicas de la invasión alemana y de la reprochable indolencia con que Francia allanó el camino a los nazis. Late en el relato un sordo desapego a la falta de voluntad política de los franceses, primero sin demostraciones de resistencia y posteriormente con una decantada estrategia de colaboracionismo por parte del Gobierno de Vichy al mando del mariscal Pétain. Las medidas afectaron a la misma Irène y a su familia, que vieron endurecer sus condiciones de vida tras establecer la línea de Demarcación impuesta como frontera interna, fruto del armisticio que el Gobierno francés firmó con Hitler para evitar una paz llena de represalias y que, a ciencia cierta, disfrazó una deshonrosa capitulación ante el III Reich. Las notas que en el cuaderno acompañan al texto de la Suite desgranan la desilusión de la autora con respecto a la actitud aquiescente de la masa anónima en la vivencia de la derrota y del colaboracionismo: una inconcebible neutralidad frente al enemigo pulula en el universo de sus personajes, anestesia- 
dos en la ausencia de arrojo y determinación de los primeros momentos de la contienda. Reflejo especular del desorden y del caos el relato transita por la anulación que impone el miedo, por la aceptación de la humillación, de la persecución y del éxodo con actitudes que oscilan de la abnegación a la violencia. Y Némirovsky va urdiendo un tapiz -merced a la técnica del narrador impersonal aprendida de Flaubert y con una clara inspiración en Guerra y paz de Tolstoi ${ }^{6}$ - donde se perfila una sociedad convulsa en una encrucijada retratada a pie de vida, con una visión en minúscula y atenta a la realidad doméstica: la ruta del éxodo derrama una galería de pueblos inundados de niños y madres hambrientos donde una silla o una cama son un lujo insólito; coches henchidos de enseres y muebles que circulan como esqueletos de hogares y atascados en el camino sin combustible; encumbrados burgueses asqueados de la plebe que tratan de salvar sus artículos de lujo; una bailarina intrigante como cicerone sexual del joven muchacho que ha huido de su familia para luchar y que vaga apabullado ante el desconcierto general; un banquero y su amante; una familia aristocrática separada en las tribulaciones de la diáspora; un cura que guía a unos huérfanos a un refugio que, provistos de una libertad inesperada sin contenciones, terminarán por asesinarlo con saña animal; pequeños hurtos de comida y de automóviles; gestos insolidarios y clasistas dentro de las privaciones... El conjunto resulta un cuadro lúcido y nada edificante del que solo se indulta a un matrimonio cuyo hijo ha resultado herido: mientras se pulveriza todo rastro de rutina o normalidad, esta pareja modesta -abandonada y aislada en el París al que regresanconserva su entereza y su dignidad.

El segundo relato -y último de los conservados-, Dolce, centra la visión en la ocupación alemana de un pueblo, Bussy, y el colaboracionismo como conflicto narrativo, gestionado como alusión a la inacción de los franceses en Tempestad en junio, aquí cobra atención cenital: la autora hace converger diversas estrategias de tensión emocional y ética en el relato de la relación mixta entre un oficial nazi y una joven francesa, Lucile, que vive con su suegra y con quien espera la llegada de su marido tras llevar, este, tiempo ilocalizable en el frente. Varios de los oficiales del destacamento son alojados en casas de burgueses de la localidad y esta circunstancia propiciará un matizado análisis de las relaciones de dominio y colaboracionismo entre los ocupados y los visitantes. La actitud férrea de resistencia de la vieja anfi-

${ }^{6}$ Al margen de reconocer sus palpables influencias, Vargas Llosa (2010) matiza: «El narrador de su historia es un fantasma, una esfinge, una ausencia locuaz. No opina, no enfatiza, no juzga: muestra, con absoluta imparcialidad... No solo la sociedad francesa desfila por ese caleidoscopio de palabras, la humanidad entera parece haber sido apresada en esas páginas cuya maniática precisión es engañosa, pues por debajo de ella todo es dolor, desgarramiento, desánimo, tortura, envilecimiento, aunque, a veces, también, nobleza, amistad, amor y generosidad. La novela muestra cómo la vida siempre es más rica y sutil que las convicciones políticas y las ideologías y cómo puede a veces sobreponerse a los odios, las enemistades y las pasiones e imponer la sensatez y la racionalidad. Las relaciones que llegan a anudarse, por ejemplo, entre muchachas campesinas y burguesas -entre ellas, algunas que tienen a sus maridos como prisioneros de guerra- y los soldados alemanes, uno de los temas más difíciles de desarrollar, están narradas con insuperable eficacia y dan lugar a las páginas más conmovedoras del libro». 
triona contrasta con la laxitud indefinida de la muchacha en su relación con el oficial alemán y sirve de referencia singular en el marco de las diferentes reacciones de los vecinos ante la llegada de los boches, como despectivamente se les tilda: de Bussy emergerá un microcosmos de conductas que oscilan desde la áspera hospitalidad de los granjeros que ven perturbada su paz doméstica al pleno colaboracionismo de las muchachas que, voluntariamente entregadas a los brazos de los soldados alemanes, buscan el medro personal. Lucile, la protagonista, hilvanará una relación estigmatizada entre los prejuicios rurales y las amonestaciones morales de los vecinos y su predisposición sensual al joven oficial Bruno, en quien encuentra un cómplice y un refugio que la inhiben de la sórdida realidad de la guerra. La trama se adereza con un resorte de tensión al esconder en su propia casa Lucile y su suegra a un granjero fugitivo de la justicia por haber asesinado a un oficial nazi que flirteaba con su esposa. La novela deja en suspensión el desenlace con la partida del destacamento y el propósito de Lucile de llevar al fugitivo a París para enrolarse en la Resistencia. Como el regimiento que deja atrás solo polvo, la relación del oficial y la muchacha se esfuma porque en el fondo se reconocen enemigos mientras la vida continúa, dejando deliberadamente abierta la estructura narrativa para los relatos que habían de suceder y que no llegaron debido a la prematura muerte de Némirovsky en Auschwitz en 1942, en las primeras fases del conflicto. No se asoma al Holocausto judío porque pereció tempranamente en él si bien despliega una paleta de emociones que van del odio a la indiferencia, de la resistencia terca a la cooperación servil, de la ambigüedad difusa a la visible oposición. Sin embargo, no encontramos en los personajes de Dolce la ausencia de la conciencia de patria de los de Tempestad en junio, más preocupados por las tribulaciones de su desarraigo que por el destino de su país: en Bussy aflora una cierto corporativismo moral de los franceses frente al enemigo. La ocupación alemana despierta el pequeño infierno del pueblo y desnuda la hipocresía de un doble rasero para medir la ética propia y la ajena: nada más llegar el oficial Bruno recibe en su despacho un alud de notas delatoras con las que los vecinos se incriminaban unos a otros, símbolo de las miserias y cobardías que despiertan las polaridades morales de una sociedad provinciana. Lucile va transitando hacia un estado de indeterminación en su relación con el oficial nazi, suspendida en los acordes de una melodía que interpreta Bruno al piano y que los anestesian de la realidad inmediata: la suite dentro de la Suite decanta un guiño metatextual que explica la clave del conjunto del relato en el que la cohabitación de ocupados e invasores es tan ilusoria y evanescente como las notas perecederas que dibujan el estribillo ensoñador de la pareja. Aquí el colaboracionismo muestra su cara siniestra en la actitud del aristócrata que compra sus privilegios con prebendas a los nazis, en la decidida repulsa de los pueblerinos que desaprueban la convivencia de Lucile y Bruno al tiempo que la rentabilizan para recuperar recuerdos y enseres de una casa desmantelada por las tropas o para ocultar al granjero fugitivo. Dolce es una antítesis irónica en la que se asoma la capacidad desintegradora de la dignidad que toda guerra precipita y un retrato inmisericorde de las congestionadas individualidades, bajo la apariencia serena de una ocupación militar civilizada que va minando paulatinamente el espejismo de la cohabitación entre civiles y soldados. 
Inspirada libremente en el relato de Némirovsky, Saul Dibb filmó en 2015 la versión cinematográfica de Dolce, interpretada por Michelle Williams y Matthias Schoenaerts en los papeles protagonistas y a Kristin Scott Thomas en el personaje de la viuda y detestable Angelier, rejuvenecida con respecto al homólogo literario pero tan ácida de espíritu y tan inflexible frente al opresor como en la novela. El film traiciona la identidad de la novela prolongando la secuencia final de la partida del regimiento ante las sospechas de que Lucile, que ha obtenido un salvoconducto para ir a París en busca de medicinas, esconda otras intenciones. Esta argucia para trasladar oculto en el maletero del coche al granjero fugitivo y ponerlo a salvo en la Resistencia es descubierta en uno de los puestos de control y, tras un enfrentamiento, logran abatir a los dos guardias. En ese instante llega Bruno, que ha sospechado de Lucile tras el olor de tabaco masculino detectado en un registro en casa de las Angelier. El reencuentro del oficial y la muchacha está inteligentemente provisto de tensión y de intención reprimidos con una admirable vuelta de tuerca: el oficial Bruno facilita la huida mientras los amantes se disuelven en un adiós cargado de silencios elocuentes y gestos contenidos.

La historia de Lilly Wust, la mujer insatisfecha de un oficial nazi, y Felice Schragenheim, alemana judía homosexual que trabajaba en un periódico del régimen para proporcionar información a la Oposición, fue recreada en la película Aimée et Jaguar, escrita y dirigida por Max Färberböck en 1999. En La lista de Schindler (Steven Spielberg, 1993) también asoma una turbulenta relación entre Amon Goeth, personificación del nazismo en estado puro, y su criada Helen. Estos amores oblicuos hilvanados en la ficción recrean relaciones que bien pudieron existir en la realidad, como la célebre pareja formada por una judía prisionera en Auschwitz, Agnes Veronik Erdös, y un soldado de las Waffen-SS, Gustav Palm, celebrada en su tiempo, si bien sus identidades fueron desveladas tras la Segunda Guerra Mundial.

No solo en la Suite francesa la autora indagó en los resortes de la guerra y en sus molestas consecuencias de desorden cotidiano: en Los bienes de este mundo cubre el período que va de la Primera Guerra Mundial hasta el comienzo de la Segunda; centrada en la burguesía provinciana se aleja de la mirada épica sin referencias tampoco al hecho judío para mostrar el advenimiento de la muerte o de la desgracia; a propósito de esta novela por entregas Carlos Zanón (2014) afirma que

comprobamos cómo les afecta, cómo luchan por seguir adelante. Las hijas acaban convertidas en sus madres, los padres en sus hijos, y las guerras en una misma guerra. Todo es inevitable. Es soberbia su descripción de una sociedad que no quiere ver lo que se avecina. Que no busca culpables, que espera que el desastre pase por encima de ellos y nadie repare en sus vidas insignificantes. El miedo, los refugiados, la vida abriéndose paso entre la destrucción. Todo eso es enunciado magistralmente.

La ausencia del problema judío en sus páginas y su colaboración con el diario Gringoire, de signo antisemita, en donde publicó, ha levantado sospechas en la actitud de la autora: si bien no tuvo la oportunidad de dar cabida al Holocausto ni al horror que trajo consigo debido a su temprana muerte, sí sufrió en carne propia las estranguladoras normas para una vida en libertad desde los primeros Estatutos de los Judíos en octubre de 1940 y la Ley de junio de 1941 que los sustituyó para precipi- 
tar las detenciones y las deportaciones a los campos de concentración. Némirovsky prefirió auspiciar en sus narraciones a las vidas minúsculas, al fluir anónimo de las gentes sin conciencia ni preocupaciones trascendentales a quienes la guerra, con su desorden y con la progresiva liquidación de la dignidad, va minando inexorablemente: la tibieza se transformará en la Suite en mirada directa al nazismo, al colaboracionismo y a la cobardía. Esa despreocupación de la masa, ese subsistir tratando de sortear los escollos de una situación adversa, esa carencia absoluta de rebeldía y de lucha contra la ocupación, esa asepsia nihilista de la resiliencia en coyunda con la negligencia del Gobierno que se sugieren implícitamente en sus narraciones son proporcionalmente inversas a las reflexiones y preocupaciones de la autora ante la realidad inminente. En un encabezado a las notas metatextuales del cuaderno escribe apenas dos meses antes de morir: «Para levantar un peso tan enorme,/ Sísifo, se necesitaría tu coraje./ No me faltan ánimos para la tarea,/ mas el objetivo es largo y el tiempo corto» (2015: 418). Murió gaseada el 17 de agosto de ese mismo año.

En sintonía con la alarma de Irène ante el desastre inminente, queremos cerrar nuestras palabras con una de las más sarcásticas visiones de los amores oblicuos entre nazis y judíos bajo el embozo de la parodia lúcida y de la ironía festiva. En otra de las visiones de los preliminares de la Guerra, el film Cabaret (Bob Fosse, 1972), basado en la novela de Christopher Isherwood Adiós a Berlín (1939) acierta a abordar precozmente el incipiente problema del antisemitismo y de las relaciones mixtas con inteligente y crítica perspectiva: el tema «If you could see her through my eyes» interpretado por Joel Grey enuncia desde una apuesta expresionista la visión del antisemitismo, consecuencia inexorable de uno de los capítulos más infames de la civilización occidental: el de la guerra y sus, a pesar de todo, oblicuos amores.

\section{Referencias bibliográficas}

Chaves Nogales, Manuel (2011): Lo que ha quedado del imperio de los zares. Sevilla: Renacimiento.

Coetzee, J. M. (2008): «Irène Némirovsky: The Dogs and the Wolves». The New York Review of Books, 20 de noviembre. En: http://www.nybooks.com/articles/archives/2008/nov/20/irene-nemirovsky-the.dogs-the-wolves/?pagination=false [Consulta: mayo 2016].

DiBB, Saul (dir.) (2005): Suite francesa. Coproducción Gran Bretaña-Francia-Bélgica-Canadá. FÄRBERBÖCK, Max (dir.) (1999): Aimée \& Jaguar. Alemania.

Fosse, Bob (dir.) (1972): Cabaret. EEUU.

GimÉnEZ CORBATÓN, José (1999a): «Irène Némirovsky. Literatura de puño cerrado». Quimera 182: 51-57.

- (1999b): «Irène Némirovsky. Literatura de puño cerrado (y 2)». Quimera 183: 45-50.

KERSHAW, Angela (2007): «Finding Irène Némirovsky». French Cultural Studies 18: 59-81.

- (2009): Before Auschwitz. Irène Némirovsky and the Cultural Landscape of Inter-war France. New York/Oxon: Routledge.

MANRIQUE SABOGAL, Winston (2006): «Los libreros premian Suite francesa». El País, 2 de junio. 
MARTí, Octavi (2004): «Irène Nemirovsky, una escritora resucitada». El País, 5 de diciembre.

- (2006): «Hallado un nuevo tesoro de Némirovsky». El País, 30 de diciembre.

- (2007): «Un odio cuestionado». El País, 23 de febrero.

NÉmIRovsKy, Irène (2006): David Golder. Trad. J. A. Soriano Marco. Barcelona: Salamandra.

- (2015): Suite francesa. Trad. J. A. Soriano Marco. Barcelona: Salamandra, 24a edición.

PHILIPPONNAT, Olivier (2009): «Les «ambigüités» d'Irène Némirovsky». La Vie des Idées, 22 de diciembre. En: http://www.laviedesidees.fr/Les-ambiguites-d-Irene-Nemironvsky.html [Consulta: mayo 2016].

PhILIPPONNAT, Olivier y Patrick LeINHARDT (2007): La vie d'Irène Némirovsky. París: Grasset-Denoël.

SÁNCHEZ, J. Jorge (2015): «La literatura de la Shoah. El canto del pueblo judío asesinado». Catalunya vanguardista, 23 de mayo. En: http://www.catalunyavanguardista.com/catvan/la-literatura-de-la-shoah/ [Consulta: junio 2016].

SANZ, María Aixa (2007): «Irène Némirovsky y el abandono». Almiar 33. En: http://www.margencero.com/articulos/aixa/irene_nemirovsky.htm [Consulta: mayo 2016].

Solano, Francisco (2005): «Observación de la guerra». El País, 5 de noviembre.

SPIELBERG, Steven (dir.) (1993): La lista de Schindler. EEUU.

VARgas LlosA, Mario (2010): «Bajo el oprobio». El País, 22 de agosto.

ZANÓN, Carlos (2014): «Irène Némirovsky y el dragón». El País, 4 de julio. 